\title{
Association between physical activity by number of steps and nutritional status in adolescents of Mexico City
}

\author{
Claudia Radilla $^{1}$, Rey Gutiérrez ${ }^{1}$, Salvador Vega ${ }^{1}$, Jesús Pérez $^{1}$, Marcela Vazquez ${ }^{1}$ and \\ María Radilla ${ }^{2}$ \\ ${ }^{1}$ Autonomous Metropolitan University Campus Xochimilco, Mexico City, Mexico and \\ ${ }^{2}$ Foundation Aprende con Reyhan A.C., Mexico City, Mexico
}

\section{Abstract}

An imbalance in energy expenditure can be the main cause of overweight and obesity. Some factors that increase it are the raise in the consumption of hypercaloric foods and the tendency to decrease physical activity. The aim of this study was to determine the association of physical activity by number of steps with the nutritional status of adolescents in Mexico City. A sample of 1457 first-grade adolescents from high school was obtained. To measure the number of steps in the adolescents, a Tanita ${ }^{\circledR}$ FB-731 pedometer was used. For the determination of physical activity, the cut points proposed by Tudor and Bassett were used. Likewise, anthropometric measures were taken and through the use of Who Anthro Plus program, the nutritional status diagnosis was obtained. The obtained data was analyzed with the statistical package IBM SPSS Statistics ${ }^{\circledR}$ version 20.0 for Windows. It was found that highly active and active adolescents have a lower prevalence of obesity $(8.0 \%$ and $6.3 \%$, respectively), in comparison with adolescents who classify on a typical day $(28.5 \%)$, or slightly active $(14.2 \%)$, finding a high significant difference $(\mathrm{p}<0.01)$. In the present study it was found that adolescents with greater physical activity have lower prevalence of obesity, results that agree with the literature, which highlight the importance of encourage adolescents to be more active to reduce the prevalence of overweight and obesity.

\section{Conflict of Interest}

There is no conflict of interest 